\title{
Comparison of complications of open and laparoscopic appendectomy
}

\author{
Yahya Çelik, @ Ozan Andaç Erbil \\ Department of General Sergery, Gebze Fatih State Hospital, Kocaeli, Turkey
}

\begin{abstract}
Introduction: Evaluations of laparoscopic appendectomy (LA) and open appendectomy (OA) as surgical treatment for acute appendicitis (AA) have yielded varying results. This assessment of the results observed at a single institution and some of the literature findings is provided as a contribution to the discussion about the superiority of different techniques in different patient groups.

Materials and Methods: The patient charts and electronic data of 1587 patients who underwent an OA or LA procedure between June 2014 and August 2018 were retrospectively reviewed. Patients younger than 18 years of age and patients with any pathology other than AA were excluded from the study. A total of 1423 patients, 877 males $(61.6 \%)$ and 546 females (38.4\%), were included in the study. Patients who underwent OA were classified as Group I $(n=771,54.2 \%)$ and patients who underwent LA comprised Group II $(n=652,45.8 \%)$.

Results: The mean age of the patients was $32.27 \pm 11.85$ years, the mean duration of the operation was $59.77 \pm 20.24$ minutes, the mean length of follow-up was $24.46 \pm 13.70$ months, and the mean length of hospital stay was $1.61 \pm 1.14$ days. The mean duration of the procedure was shorter in the OA group $(58.8 \pm 20.9$ minutes) compared with the LA group $(60.88 \pm 19.38$ minutes $)(p=0.002)$. The percentage of female patients was higher in the LA group (42.94\%) than in the OA group $(34.50 \%)(p=0.001)$. The wound site infection rate was higher in the OA group (9.9\%) compared with the LA group (9.05\%). The rate of complications requiring hospitalization was higher after OA (3.5\%) compared with LA (2.3\%), and the rate of complications requiring re-operation was also higher with OA $(1.03 \%)$ compared with LA $(0.3 \%)$. However, the difference in all parameters was statistically insignificant.

Conclusion: Both OA and LA are safe methods to treat AA. The rate of postoperative complications and the length of an OA operation have been decreasing progressively over the years; however, a preference for $L A$ has been increasing over time. As for gallbladder operations, LA is likely to be the gold standard in AA treatment.

Keywords: Acute appendicitis; appendectomy; laparoscopic; open appendectomy.
\end{abstract}

\section{Introduction}

Acute appendicitis (AA) is the most prevalent surgical disease with a $7-8 \%$ of life long incidence risk. ${ }^{[1]}$ Appendectomy is the most preferred treatment method. McBurney ${ }^{[2]}$ have described still widely used appendectomy technique in 1894. In 1980, Semm ${ }^{[3]}$ has performed the first laparoscopic appendectomy. However, a genuine "laparoscopic revolution” has occurred after Erich Muhe has performed 
the first laparoscopic cholecystectomy in 1985 by employing Semm's technique and instruments. ${ }^{[4]}$ Initially laparoscopy wasn't a widely used technique, because it wasn't considered a safe method. Today, laparoscopic surgery is the primary choice in many surgical procedures. Open appendectomy (OA) with its low mortality and morbidity rates is considered as the golden standard for AA, but after proven safety of the laparoscopic appendectomy (LA) it has been increasingly employed in surgical treatment of AA. ${ }^{[5,6]}$ Shorter hospital stay and rapid return to normal daily activities, less post-op pain and lower wound site infection are reported as the advantages of LA. ${ }^{[5,7,8]}$ In addition, laparoscopic approach is important because of probable misdiagnosis especially in fertile women. ${ }^{[9]}$ However, in the studies of Tzovaras et al..$^{[9]}$ and Ingraham et al., ${ }^{[10]}$ higher cost and longer operation time was reported and no additional benefit was recorded in patient recovery. Technological improvements and increasing experience of the surgeons on laparoscopy progressively improves the positive results. ${ }^{[6]}$ Debate over superiority of LA or OA in surgical treatment of AA in particular patient groups is still ongoing. Our aim is to assess our results under the guidance of literature in order to make a contribution in determination of the optimal surgical procedures for acute appendicitis treatment.

\section{Materials and Methods}

After approval of the local ethics committee patients chart and electronic data of 1587 patients who have undergone appendectomy by OA or LA in our hospital between June 2014 and August 2018 were retrospectively reviewed. Patients requiring switch to open surgery after the laparoscopically initiated surgery, negative laparascopi or laparatomi, patients younger than 18 years, pregnant patients and patients having additional pathology other than acute appendicitis have been excluded from the study. Since most of the pathology findings could not be reached, they were not included.

Age, sex, duration of operation, hospital stay, complications requiring post-op hospitalization and wound site infections were assessed. The results were compared statistically and evaluated under the guidance of the literature.

The diagnosis was made by USG control or CT after physical examination. Under general anesthesia LA was performed by a three-trocar technique. A $10 \mathrm{~mm}$ port was placed at the umbilicus, first $5 \mathrm{~mm}$ port was placed in the left lower abdominal quadrate and secont $5 \mathrm{~mm}$ port was placed in the suprapubic area. Appendix stump was lig- ated by endo-loops (Vicryl 2/0 ethicon) and divided with laparoscopic scissors. Using $5 \mathrm{~mm}$ optics the specimen was extracted through the umblical trocar. A drain was placed into the rectovesical area, if necessary. OA was performed McBurney incision. The mesoappendix was ligated, and the appendix was divided at the base and removed. A drain was placed into the rectovesical area, if necessary. Preoperative $1 \mathrm{~g}$ cephazolin sodium was given i.v. to all patients prophylactically. Antibiotherapy continued during the hospital stay in all perforated patients. It was completed to ten days orally after the patients were discharged. In non-perforated patients antibiotherapy wasn't maintained after prophylactic use.

Statistical analysis was carried out by SPSS version 17.0. Conformity of variables to normal distribution was assessed by histogram graphics and Kolmogorov-Smirnov test. Mean, standard deviation, median and minimummaximum were used in descriptive analysis. Categorical data were compared by Pearson Chi square and Fisher's Exact Test. Inter group assessment of variables with nonnormal distribution (non-parametric) was carried out by using Mann-Whitney U Test. Values $\mathrm{p}<0.05$ were considered statistically significant.

\section{Results}

877 male $(61.6 \%)$ and 546 female $(38.4 \%)$ patients totaling 1423 were included into the study. 771 (54.2\%) of the patients have undergone open appendectomy and 652 patients (45.8\%) have undergone laparoscopic appendectomy. Mean age of patients was $32.27 \pm 11.85$ years, duration of operation was $59.77 \pm 20.24 \mathrm{~min}$, follow up was $24.46 \pm 13.70$ months and hospital stay was $1.61 \pm 1.14$ days.

In 42 patients (2.9\%) complications requiring hospitalization have occurred. $9(0.6 \%)$ patients had subileus, 9 $(0.6 \%)$ patients had wound site infection, $9(0.6 \%)$ patients had post-op abdominal pain, 7 (0.5\%) patients had intraabdominal abscess, $3(0.2 \%)$ patients had stump leakage, $2(0.1 \%)$ patients had bridge ileus and $1(0.07 \%)$ patient had incisional hernia, $1(0.07 \%)$ patient had trocar site hernia and $1(0.07 \%)$ patient had omentum as content of drain site hernia. In 10 patients $(0.7 \%)$ requiring hospitalization operation was indicated.

Out of 7 patients with abdominal abscess only two who had this complication after OA were re-operated. After drainage of the abscess by open method a drain was inserted. In two patients bridge ileus has occurred after OA. Both patients were treated (by bridectomy). There was no 
bridge ileus in patients who had undergone LA. Stump leakage has occurred in two patients after OA and in one patient after LA. In one patient primary closure was done but in two patients ileostomy was established in addition to primary closure due to abdominal contamination and co-morbidity. There was no mortality (Table 1).

Assessment of patients according to indication for re-hospitalization and re-operation in terms of type of operation didn't reveal any significant result ( $p>0.05)$.

Age, sex, duration of the operation and hospital stay was compared according to the type of operation. Mean duration of operation with open appendectomy was (58.82 $\pm 20.90 \mathrm{~min})$ was shorter than laparoscopic appen- dectomy $(60.88 \pm 19.38 \mathrm{~min})(\mathrm{p}=0.002)$. Mean follow up of patients who had undergone laparoscopic appendectomy (26.60 \pm 13.37 months) was longer compared to laparoscopic appendectomy ( $21.92 \pm 13.67$ months) $(\mathrm{p}<0.001)$. Percentage of male patients $(65.50 \%)$ within open appendectomy cases was higher compared to laparoscopic appendectomy (57.06\%) and percentage of female patients (42.94\%) were higher with laparoscopic appendectomy compared to open appendectomy $(34.50 \%)(\mathrm{p}=0.001)$ (Table 2).

\section{Discussion}

Lower incidence of surgical site infection, shorter duration of post-op hospital stay, less pain, lower incidence

Table 1. Percentage of the complications according to the type of operation in terms of post-op indication for rehospitalization hospital stay and re-operation

\begin{tabular}{|c|c|c|c|c|c|}
\hline & \multicolumn{4}{|c|}{ Type of operation } & \multirow[t]{3}{*}{$\mathbf{p}$} \\
\hline & \multicolumn{2}{|c|}{$\begin{array}{c}\text { Open } \\
\text { appendectomy } \\
(n=771)\end{array}$} & \multicolumn{2}{|c|}{$\begin{array}{l}\text { Laparoscopic } \\
\text { appendectomy } \\
(n=652)\end{array}$} & \\
\hline & $n$ & $\%$ & $\mathbf{n}$ & $\%$ & \\
\hline \multicolumn{6}{|l|}{ Complications requiring re-hospitalization } \\
\hline Abscess drainage & 77 & 9.99 & 59 & 9.05 & 0.549 \\
\hline Total & 27 & 3.50 & 15 & 2.30 & 0.210 \\
\hline Intraabdominal abscess & 5 & 0.64 & 2 & 0.30 & 0.738 \\
\hline Subileus & 5 & 0.64 & 4 & 0.61 & \\
\hline Wound site infection & 5 & 0.64 & 4 & 0.61 & \\
\hline Bridge lleus & 2 & 0.25 & 0 & 0.00 & \\
\hline Incisional hernia & 1 & 0.12 & 0 & 0.00 & \\
\hline Postop abdominal pain & 6 & 0.77 & 3 & 0.46 & \\
\hline Trocar site hernia & 0 & 0.00 & 1 & 0.15 & \\
\hline Stump leakage & 2 & 0.25 & 1 & 0.15 & \\
\hline Omentum as content of drain site hernia & 1 & 0.12 & 0 & 0.00 & \\
\hline \multicolumn{6}{|l|}{ Complications requiring re-operation } \\
\hline Total & 8 & 1.03 & 2 & 0.30 & 0.1 \\
\hline Intraabdominal abscess & 2 & 0.25 & 0 & 0.00 & 0.323 \\
\hline Subileus & 0 & 0.00 & 0 & 0.00 & \\
\hline Woundsite infection & 0 & 0.00 & 0 & 0.00 & \\
\hline Bridge lleus & 2 & 0.25 & 0 & 0.00 & \\
\hline Incisional hernia & 1 & 0.12 & 0 & 0.00 & \\
\hline Postop Abdominal pain & 0 & 0.00 & 0 & 0.00 & \\
\hline Trocar site hernia & 0 & 0.00 & 1 & 0.15 & \\
\hline Stump leakage & 2 & 0.25 & 1 & 0.15 & \\
\hline Omentum as content of drain site hernia & 1 & 0.12 & 0 & 0.00 & \\
\hline
\end{tabular}


Table 2. Comparison of age and duration of the operation and hospital stay according to the type of operation

\begin{tabular}{|c|c|c|c|c|c|}
\hline & \multicolumn{4}{|c|}{ Type of operation } & \multirow[t]{3}{*}{$\mathbf{p}^{\prime}$} \\
\hline & \multicolumn{2}{|c|}{ Open appendectomy } & \multicolumn{2}{|c|}{ Laparoscopic appendectomy } & \\
\hline & Mean $\pm S D$ & Median & Mean $\pm S D$ & Median & \\
\hline Age & $32.19 \pm 11.89$ & 30.00 & $32.36 \pm 11.81$ & 31.00 & 0.796 \\
\hline Duration of operation & $58.82 \pm 20.90$ & 55.00 & $60.88 \pm 19.38$ & 60.00 & 0.002 \\
\hline Follow up & $26.60 \pm 13.37$ & 25.22 & $21.92 \pm 13.67$ & 20.84 & $<0.001$ \\
\hline Duration of hospital stay & $1.58 \pm 1.17$ & 1.00 & $1.65 \pm 1.11$ & 1.00 & 0.061 \\
\hline \multicolumn{6}{|l|}{ Sex, n (\%) } \\
\hline Male & \multicolumn{2}{|c|}{$505(65.50)$} & \multicolumn{2}{|c|}{$372(57.06)$} & $0.001^{2}$ \\
\hline Female & \multicolumn{2}{|c|}{$266(34.50)$} & \multicolumn{2}{|c|}{$280(42.94)$} & \\
\hline
\end{tabular}

'Mann Whitney U Test. ${ }^{2}$ Chi-SquareTest. SD: Standard deviation.

of incisional hernia and shorter time requirement for post-op recovery and returning to normal daily activities are reported as advantages of laparoscopic approach. ${ }^{[11-15]}$ However, because of lower cost, shorter duration of operation and no demand for higher surgical skills OA is still widely employed..$^{[5,1,1,16,17]}$ In a meta-analysis carried out by Li et al. ${ }^{[5]}$ it was found that in studies before 2000 duration of operation was 15.14 min longer with LA compared to OA but this difference was only $8.67 \mathrm{~min}$ in the studies that were performed in the following years. As the experience of the surgeons increase, duration of operation became closer to each other between two methods. ${ }^{[18]}$ In our study LA was mean 2,06 min longer compared to OA.

According to Tamjeed Gul et al. ${ }^{[19]}$ rate of males was higher among acute appendicitis patients compared to females. We had a similar result in our study. It was reported that LA is employed higher percentage of females compared to males. ${ }^{[20,21]}$ This may stem from higher number of conditions in females that may lead to an acute appendicitis misdiagnosis compared to males and thus desire of surgeons to start the procedure as a diagnostic laparoscopy in females and then proceed to the actual operation if needed and preference of females due to cosmetic considerations. ${ }^{[20,21]}$ In our study also LA was higher in females. Preference of LA in treatment of acute appendicitis has been progressively increasing over years. In 2000 LA preference rate was $26 \%$ and the rate was reported as $69 \%$ in 2013. ${ }^{[20]}$ In our study follow up period was longer in OA. In accordance with the literature our preference for LA has also progressively increased over years.
In the study of Sartelli et al. ${ }^{[22]}$ median age of the disease was found as 29 years and thus they have reported that the disease affects young population. We had results similar to this study. In the study of Sartelli et al. ${ }^{[22]}$ median hospital stay was 3 days, Ceresoli et al. ${ }^{[20]}$ have reported mean 5.19 days for hospital stay in their meta-analysis. In our study hospital stay was shorter and there was no statistical difference in terms of hospital stay in both groups.

In different studies varying rate of wound site infection has been reported and their mean rate was reported as $12.5 \%$ (LA) and 14\% (OA). ${ }^{[1,21,23,24]}$ In our study wound site infection rate was lower than these figures by both methods and there was no significant difference between $\mathrm{OA}$ and LA.

In the study of Sartelli et al. ${ }^{[22]}$ re-operation rate during the post-op period was reported as $1.3 \%$. In our study reoperation rate was lower with both methods compared to the study of Sartelli et al. and there was no significant difference between OA and LA. Incidence of post-op complication is reported as between $3 \%-28.7 \%$ in the literature. ${ }^{[25,26]}$ Most commonly reported complications in the literature are small intestine obstruction, surgical site infection, stump leakage, abdominal abscess and stump appendicitis. ${ }^{[27,28]}$ Abdominal abscess is a commonly encountered complication and its incidence is reported between $1.5 \%-8 \%{ }^{[28,29]}$ In our series there was stump appendicitis. Other complications and their incidence were in accordance with the literature. When compared rate of all complications, complication requiring re-hospitalization and complications requiring reoperation was lower with LA. However, the difference wasn't statistically significant. 
Limitation of our study is its design being retrospective. Moreover, returning to normal daily activities and parameters of post-op pain weren't assessed.

OA and LA are both safe methods in treatment of AA. Postop complications and duration of operation for LA have been improving during the past years. Preference of LA in treatment of acute appendicitis has been progressively increasing over years. As in gall bladder surgery AL also becomes golden standard in the treatment of AA.

\section{Disclosures}

Ethichs Committee Approval: The study was approved by the Local Ethics Committee.

Peer-review: Externally peer-reviewed.

Conflict of Interest: None declared.

\section{References}

1. Addiss DG, Shaffer N, Fowler BS, Tauxe RV. The epidemiology of appendicitis and appendectomy in the United States. Am J Epidemiol 1990;132:910-25.

2. McBurney C. IV. The Incision Made in the Abdominal Wall in Cases of Appendicitis, with a Description of a New Method of Operating. Ann Surg 1894;20:38-43.

3. Semm K. Endoscopic appendectomy. Endoscopy 1983;15:5964.

4. Litynski GS. Kurt Semm and the fight against skepticism: endoscopic hemostasis, laparoscopic appendectomy, and Semm's impact on the "laparoscopic revolution". JSLS 1998;2:309-13.

5. Li X, Zhang J, Sang L, Zhang W, Chu Z, Li X, et al. Laparoscopic versus conventional appendectomy-a meta-analysis of randomized controlled trials. BMC Gastroenterol 2010;10:129.

6. Ruffolo C, Fiorot A, Pagura G, Antoniutti M, Massani M, Caratozzolo E, et al. Acute appendicitis: what is the gold standard of treatment? World J Gastroenterol 2013;19:8799-807.

7. Cipe G, Idiz O, Hasbahceci M, Bozkurt S, Kadioglu H, Coskun $\mathrm{H}$, et al. Laparoscopic versus open appendectomy: where are we now? Chirurgia (Bucur) 2014;109:518-22.

8. McGrath B, Buckius MT, Grim R, Bell T, Ahuja V. Economics of appendicitis: cost trend analysis of laparoscopic versus open appendectomy from 1998 to 2008. J Surg Res 2011;171:e161-8.

9. Tzovaras G, Baloyiannis I, Kouritas V, Symeonidis D, Spyridakis $M$, Poultsidi A, et al. Laparoscopic versus open appendectomy in men: a prospective randomized trial. Surg Endosc 2010;24:2987-92.

10. Ingraham AM, Cohen ME, Bilimoria KY, Pritts TA, Ko CY, Esposito TJ. Comparison of outcomes after laparoscopic versus open appendectomy for acute appendicitis at 222 ACS NSQIP hospitals. Surgery 2010;148:625-35; discussion
635-7.

11. Ohtani $H$, Tamamori $Y$, Arimoto $Y$, Nishiguchi $Y$, Maeda $K, \mathrm{Hi}-$ rakawa K. Meta-analysis of the results of randomized controlled trials that compared laparoscopic and open surgery for acute appendicitis. J Gastrointest Surg 2012;16:192939.

12. Masoomi H, Mills S, Dolich MO, Ketana N, Carmichael JC, Nguyen NT, et al. Comparison of outcomes of laparoscopic versus open appendectomy in adults: data from the Nationwide Inpatient Sample (NIS), 2006-2008. J Gastrointest Surg 2011;15:2226-31.

13. Xiao Y, Shi G, Zhang J, Cao JG, Liu LJ, Chen TH, et al. Surgical site infection after laparoscopic and open appendectomy: a multicenter large consecutive cohort study. Surg Endosc 2015;29:1384-93.

14. Tümay LV, Güner OS, Zorluoğlu A. Laparoscopic Appendectomy Experience 132 Cases. Journal of Diseases of the Colon and Rectum 2010;20:115-20.

15. Bostancı Ö, Okul Ş, Yazıcı P, Işı RG, Demir U, Işı CT, et al. Akut apandisit olgularında açık ve laparoskopik ameliyat sonuçlarının retrospektif değerlendirilmesi. Şişli Etfal Tıp Bülteni 2014;48:208-12.

16. Wei B, Qi CL, Chen TF, Zheng ZH, Huang JL, Hu BG, et al. Laparoscopic versus open appendectomy for acute appendicitis: a metaanalysis. Surg Endosc 2011;25:1199-208.

17. Wilson DG, Bond AK, Ladwa N, Sajid MS, Baig MK, Sains P. Intra-abdominal collections following laparoscopic versus open appendicectomy: an experience of 516 consecutive cases at a district general hospital. Surg Endosc 2013;27:2351-6.

18. Kehagias I, Karamanakos SN, Panagiotopoulos S, Panagopoulos K, Kalfarentzos F. Laparoscopic versus open appendectomy: which way to go? World J Gastroenterol 2008;14:4909-14.

19. Gul T, Bilal M, Gul A, Sahar S, Kamran W, Akhunzada TS. Surgical site infection in open versus laparoscopic appendectomy. J Surg Pak 2014;19:22-5.

20. Ceresoli M, Zucchi A, Allievi N, Harbi A, Pisano M, Montori G, et al. Acute appendicitis: Epidemiology, treatment and outcomes- analysis of 16544 consecutive cases. World J Gastrointest Surg 2016;8:693-9.

21. Suh YJ, Jeong SY, Park KJ, Park JG, Kang SB, Kim DW, et al. Comparison of surgical-site infection between open and laparoscopic appendectomy. J Korean Surg Soc 2012;82:359.

22. Sartelli M, Baiocchi GL, Di Saverio S, Ferrara F, Labricciosa FM, Ansaloni L, et al. Prospective Observational Study on acute Appendicitis Worldwide (POSAW). World J Emerg Surg 2018;13:19.

23. Hansson J, Körner U, Khorram-Manesh A, Solberg A, Lundholm K. Randomized clinical trial of antibiotic therapy versus appendicectomy as primary treatment of acute appendicitis in unselected patients. Br J Surg 2009;96:473-81.

24. Di Saverio S, Mandrioli M, Sibilio A, Smerieri N, Lombardi R, Catena $F$, et al. A cost-effective technique for laparoscopic 
appendectomy: outcomes and costs of a case-control prospective single-operator study of 112 unselected consecutive cases of complicated acute appendicitis. J Am Coll Surg 2014;218:e51-65.

25. Emil S, Elkady S, Shbat L, Youssef F, Baird R, Laberge JM, et al. Determinants of postoperative abscess occurrence and percutaneous drainage in children with perforated appendicitis. Pediatr Surg Int 2014;30:1265-71.

26. Isaksson K, Montgomery A, Moberg AC, Andersson R, Tingstedt $B$. Long-term follow-up for adhesive small bowel obstruction after open versus laparoscopic surgery for suspected appendicitis. Ann Surg 2014;259:1173-7.
27. Gandaglia G, Ghani KR, Sood A, Meyers JR, Sammon JD, Schmid $M$, et al. Effect of minimally invasive surgery on the risk for surgical site infections: results from the National Surgical Quality Improvement Program (NSQIP) Database. JAMA Surg 2014;149:1039-44.

28. Advani V, Ahad S, Gonczy C, Markwell S, Hassan I. Does resident involvement effect surgical times and complication rates during laparoscopic appendectomy for uncomplicated appendicitis? An analysis of 16,849 cases from the ACSNSQIP. Am J Surg 2012;203:347-51; discussion 351-2.

29. Kanona H, Al Samaraee A, Nice C, Bhattacharya V. Stump appendicitis: a review. Int J Surg 2012;10:425-8. 